\title{
Online Appendix to Financial Distress, Stock Returns, and the 1978 Bankruptcy Reform Act
}

\author{
Dirk Hackbarth* $^{*}$ Rainer Haselmann ${ }^{\dagger}$ David Schoenherr ${ }^{\ddagger}$
}

October 31, 2014

*Boston University, 595 Commonwealth Avenue, Boston, MA 02215, USA. Email: dhackbar@bu.edu

${ }^{\dagger}$ University Frankfurt, Grueneburgplatz 1, 60323 Frankfurt, Germany. Email: haselmann@safe.uni-frankfurt.de

${ }^{\ddagger}$ London Business School, Regent’s Park, London NW1 4SA, UK. Email: dschoenherr@london.edu 
Table 1 displays various robustness tests of the reform effect reported in Table 7, Models 3 and 6 . Models 1-3 show the results for long-short portfolios investing in the riskiest quintile of stocks and selling the safest quintile. One concern is that in the post-BRA period more months fall into economic downturns, negatively biasing the returns of distressed firms. In Model 1, we add a recession dummy that takes the value of one for months that fall into NBER recession periods thereby capturing differences in returns of the long-short portfolio in recessionary periods compared to months without recessions. The results are not qualitatively affected by including a recession dummy. To address the concern that frequent portfolio updating biases portfolio returns by tracking only poorly performing stocks in the group of distressed stocks, whereas well performing stocks are continuously removed from the portfolio, ${ }^{1}$ we update the long-short portfolio annually in January each year for Model 2 instead of monthly. The reform effect is almost unaffected by reducing the updating frequency. In Model 3, portfolio returns are calculated by weighting each firm's return by its market capitalization. Interestingly, for value-weighted returns, there is a significantly negative premium before and after the reform. The negative premium for value-weighted portfolios is in line with the findings in Campbell, Hilscher, and Szilagyi (2008) for an earlier and shorter time period (they study distress risk premia after 1980 using the same hazard model). The differences between equal- and value-weighted portfolios are consistent with earlier findings in the literature (Vassalou and Xing (2004), Griffin and Lemmon (2002), Campbell, Hilscher, and Szilagyi (2008)). In value-weighted portfolios the smallest and most distressed stocks are given only marginal weight making their impact on portfolio returns negligible. Notably, the reform's effect on alphas remains reliably negative (i.e., $-0.89 \%$ ) for value-weighted portfolios. Overall, the results of Table 1 support our first hypothesis that the distress risk premium declines as a consequence of the BRA and the associated increase in shareholder bargaining power. Models 4 and 5 replicate the robustness test with a recession dummy (Model 4) and annually updated portfolios (Model 5) for firm-level monthly returns. We regress monthly returns on a monthly-updated default rank measure ranging from one for the safest quintile of firms to five for the most distressed quintile of firms. The results are qualitatively unaffected. Model 6 controls for industry fixed effects. Controlling for industry effect to rule out the possibility that changes in portfolio returns in the time-series are driven by changes in the industry composition of distress risk portfolios. Including industry-fixed effects leaves the results qualitatively unaffected.

\footnotetext{
${ }^{1}$ This concern would, however, apply to both the pre-BRA and post-BRA periods and therefore should not affect the relative differences in risk premia across periods.
} 


\section{Table 1. Reform Effect - Robustness Tests}

\begin{tabular}{|c|c|c|c|c|c|c|}
\hline \multicolumn{7}{|l|}{ Panel A. Pre-Reform } \\
\hline Alpha & 0.44 & -0.18 & $-0.88^{* * *}$ & $-0.15^{* * *}$ & $-0.25^{* * *}$ & $-0.20^{* * *}$ \\
\hline$t$-statistic & & {$[0.52]$} & {$[2.85]$} & {$[2.95]$} & {$[4.31]$} & {$[4.12]$} \\
\hline Market Beta & 0.02 & -0.00 & 0.10 & $-0.02^{*}$ & $-0.03^{* * *}$ & $-0.03^{* *}$ \\
\hline$t$-statistic & {$[0.25]$} & {$[0.0$} & {$[1.4$} & {$[1.67]$} & {$[2.70]$} & {$[2.43]$} \\
\hline Value Beta & $0.94^{* * *}$ & $0.82^{* * *}$ & $1.28^{* * *}$ & $0.15^{* * *}$ & $0.16^{* * *}$ & $0.14^{* * *}$ \\
\hline$t$-statistic & {$[6.79]$} & {$[5.87]$} & {$[10.22]$} & [6.38] & {$[7.92]$} & {$[6.01]$} \\
\hline Size Beta & $1.16^{*}$ & $1.35^{* * *}$ & $1.67 * * *$ & $0.32^{* * *}$ & $0.34^{* * *}$ & $0.31 * * *$ \\
\hline$t$-statistic & {$[9.0$} & {$[10.77]$} & [14.95] & {$[15.21]$} & [18.68] & {$[14.12]$} \\
\hline Momentum Beta & $-0.64 * * *$ & $-0.71 * * *$ & $-0.52^{* * *}$ & & $-0.06 * * *$ & \\
\hline$t$-statistic & {$[4.84]$} & {$[6.48]$} & & & & \\
\hline ations & & 46 & & & & 3673 \\
\hline \multicolumn{7}{|l|}{ Panel B. Post-Reform } \\
\hline & -0.51 & $-1.24^{* *}$ & $-1.77^{* * *}$ & $-0.27^{* * *}$ & $-0.59 * * *$ & $-0.40^{* * *}$ \\
\hline$t$-s & & & & [3.53] & {$[7$.} & \\
\hline Mar & -0. & -0. & 0.1 & -0.0 & $-0.08 * * *$ & $-0.03^{*}$ \\
\hline & & & & & & \\
\hline Value & 0.37 & $0.36^{*}$ & 0.65 & $0.07^{*}$ & $0.04 *$ & $0.08^{* * *}$ \\
\hline & & & & {$[3$.} & & \\
\hline Size I & $0.75^{* * *}$ & $0.91^{* * *}$ & $1.23^{* * *}$ & $0.15^{* * *}$ & $0.19^{* * *}$ & $0.17^{* * *}$ \\
\hline & [5 01$]$ & {$[4.90]$} & {$[5,85]$} & [4.84] & {$\left[\begin{array}{ll}6 & 37]\end{array}\right]$} & {$[5.41]$} \\
\hline Momentum Beta & $-0.53^{* * *}$ & $-0.59 * * *$ & $-0.69 * * *$ & $-0.05^{*}$ & $-0.11 * * *$ & $-0.06 * *$ \\
\hline & [3.91] & {$[3.74]$} & {$[4.37]$} & & {$[5.62]$} & {$[2.28]$} \\
\hline Observations & 46 & 46 & 46 & 459 & 483 & 4594 \\
\hline \multicolumn{7}{|l|}{ Panel C. Reform Effect } \\
\hline Alpha & $-1.04^{*}$ & $-1.06^{*}$ & $-0.89^{*}$ & -0 . & $-0.34^{* * *}$ & $-0.19^{* *}$ \\
\hline tistic & & & & & & {$[2.46]$} \\
\hline et Beta & -0.15 & -0.12 & 0.08 & -0.02 & $-0.05 * *$ & 0.01 \\
\hline & {$[1.1$} & {$[0.8$} & & {$[0.9$} & {$[2.59]$} & {$[0.32]$} \\
\hline Beta & $-0.57^{* *}$ & $-0.46^{*}$ & $-0.63 * * *$ & $-0.08^{* *}$ & $-0.12^{* * *}$ & $-0.07 * *$ \\
\hline & {$[26$} & {$[1.90]$} & [2, 601] & {$[2.51]$} & [4.27] & {$[2.25]$} \\
\hline Size Beta & $-0.44^{* *}$ & -0.4 & -0.4 & $-0.17 * * *$ & $-0.16^{* * *}$ & $-0.11^{* * *}$ \\
\hline & {$[2.2$} & {$[1.98]$} & & {$[4.2$} & {$[4$.} & [2.93] \\
\hline Momentum Beta & 0.1 & 0.11 & -0.17 & -0.00 & $-0.05^{*}$ & -0.01 \\
\hline & & & & & & {$[0.20]$} \\
\hline tions & 92 & 92 & 92 & 8267 & 8522 & 8267 \\
\hline & monthly & yearly & monthly & monthly & yearly & monthly \\
\hline Val & no & no & yes & - & - & - \\
\hline & yes & no & no & yes & no & no \\
\hline Industry FE & - & - & - & no & no & yes \\
\hline
\end{tabular}

For the results in Models 1-3, we sort stocks into quintiles according to their default measure and construct a long-short portfolio investing in the riskiest twenty percent and going short in the safest twenty percent of stocks. We skip one month between monthly portfolio formation and portfolio returns. We show the results from the regression of monthly equal weighted returns over the risk free rate on the ? four factor model. For the results in Models 4-6 in this table, we estimate alphas and betas for the pre-reform and post-reform period separately for each firm by regressing returns over the risk free rate on the four factor model. We compute the average of each firms default measure quintile separately for both periods and then run cross-sectional regressions separately for firm-level alphas and betas on firms' average default rank. Results for the pre-reform period from January 1975 to October 1978 are in Panel A, the results from the post-reform period from March 1981 to December 1984 in Panel B. Panel C displays the differences between the post-reform and pre-reform period estimates. The bottom of the table displays information on the portfolio updating frequency, portfolio weighting, and the inclusion of recession dummies and industry fixed effects. ${ }^{*}$ indicates statistical significance at the $10 \%,{ }^{* *}$ at the $5 \%$, and ${ }^{* * *}$ at the $1 \%$ level. 